\title{
Distance supervision in nursing: a reality desired by nurses
}

\author{
Supervisão à distância em enfermagem: uma realidade desejada pelos enfermeiros \\ Supervisión a distancia en enfermería: una realidad que los enfermeros desean \\ Inês Alves da Rocha e Silva Rocha*; Margarida Reis Santos**; Regina Maria Ferreira Pires***
}

\begin{abstract}
Background: Distance supervision strategies facilitate the supervision process since the supervisee has easier access to the supervisor for obtaining support.

Objectives: To identify the frequency of implementation of distance supervision strategies, as well as the strategies that nurses would like to see implemented more often in hospital and primary health care settings.

Methodology: Descriptive, exploratory and cross-sectional study with a quantitative approach using a sample of 273 nurses. Data were collected through the Questionnaire of Frequency Assessment of Clinical Supervision in Nursing Strategies (Questionário de Avaliação da Frequência de Estratégias de Supervisão Clínica em Enfermagem).

Results: Nurses would like distance supervision strategies to be more often implemented. In comparison with hospital nurses, primary health care nurses argue that distance supervision strategies by telephone and email should be more often implemented.

Conclusion: The study contributes to improve the knowledge on Clinical Supervision in Nursing, particularly on distance supervision strategies.
\end{abstract}

Keywords: nursing; mentors; professional competence; quality improvement

\section{Resumo}

Enquadramento: As estratégias de supervisão à distância facilitam o processo supervisivo, permitindo ao supervisionado aceder mais facilmente ao supervisor para obtenção de apoio.

Objetivos: Identificar a frequência com que as estratégias de supervisão à distância são implementadas; identificar as estratégias de supervisão à distância que os enfermeiros gostariam que fossem mais frequentemente implementadas em contexto hospitalar e de cuidados de saúde primários.

Metodologia: Investigação quantitativa, de cariz descritivo exploratório e natureza transversal. Amostra constituída por 273 enfermeiros. Colheita de dados através do Questionário de Avaliação da Frequência de Estratégias de Supervisão Clínica em Enfermagem.

Resultados: Os enfermeiros desejam que as estratégias de supervisão à distância sejam mais frequentemente implementadas. Os enfermeiros dos cuidados de saúde primários, comparativamente com os do hospital, pretendem que as estratégias de supervisão à distância telefone e e-mail sejam mais frequentemente implementadas.

Conclusão: O estudo contribuiu para aprofundar o conhecimento na área da supervisão clínica em enfermagem, nomeadamente das estratégias de supervisão à distância.

Palavras-chave: enfermagem; mentores; competência profissional; melhoria de qualidade

\footnotetext{
* MSc., Nurse Specialist in Rehabilitation Nursing, São João Hospital Center, E.P.E. , 4200-319, Porto, Portugal [inesarsrocha@gmail.com]. Contribution to the article: literature search; dat Porto, Portugal [inesarsrocha@gmail.com]. Contribution to the article: literature search; data
collection; statistical treatment and analysis; data analysis and discussion; article writing. Address collection; statistical treatment and analysis; data analysis and discussion; article writing. Address
for correspondence: Rua Álvaro Castelōes, n. ${ }^{\circ} 463,1^{\circ}$ frente N, bloco b, Matosinhos, 4200-365, Porto, Portugal.

**PhD., Coordinating Professor, Nursing School of Porto, Center for Health Technology and Services Research (CINTESIS), 4200-072, Porto, Portugal. Contribution to the article: data analysis and discussion.

*** MSc., Assistant Professor, Nursing School of Porto, 4200-072, Porto, Portugal. Contribution to the article: data analysis and discussion.
}

\section{Resumen}

Marco contextual: las estrategias de supervisión a distancia (ESAD) facilitan el proceso de supervisión y permiten al supervisando acceder más fácilmente al supervisionador para obtener apoyo.

Objetivos: identificar la frecuencia con la que se emplean las ESAD; identificar las ESAD que a los enfermeros les gustaría que se emplearan con más frecuencia en el contexto hospitalario y de atención primaria.

Metodología: investigación cuantitativa, descriptiva, exploratoria y de carácter transversal. La muestra la constituyeron 273 enfermeros. La recogida de datos se realizó a través del Cuestionario de Evaluación de la Frecuencia de Estrategias de Supervisión Clínica en Enfermería.

Resultados: los enfermeros desean que las ESAD se empleen con más frecuencia. Los enfermeros de atención primaria, en comparación con los de los hospitales, pretenden que las ESAD teléfono y correo electrónico se empleen con más frecuencia.

Conclusión: el estudio ha contribuido a profundizar en el conocimiento en el área de la supervisión clínica en enfermería, en particular de las ESAD.

Palabras clave: enfermería; mentores; competencia profesional; mejoramiento de la calidad

Received for publication: 30.03 .15

Accepted for publication: 05.07 .16 


\section{Introduction}

Given the changes in healthcare systems, the scientific and technological advances, the emergence of new communication and information strategies, and the cutbacks in human and financial resources, healthcare organizations have been adopting mechanisms to ensure the quality of clinical practices in adverse situations. In these circumstances, Clinical Supervision in Nursing (CSN) has gradually emerged in health contexts as a support process of nurses' professional practice and has promoted the development of skills and professional responsibility (Macedo, 2012; McColgan \& Rice, 2012; Evans \& Marcroft, 2015).

Clinical supervision allows nurses to cope with the challenging nature of care provision and the increasing demands of healthcare management within organizations. This work method includes consulting, guidance, management and leadership, and focuses on the development of clinical practice through reflection, guidance and professional support (Silva, Pires, \& Vilela, 2011; Francke \& Graaff, 2012; Dilworth, Higgins, Parker, Kelly, \& Turner, 2013; Cruz, Carvalho, \& Sousa, 2014).

Our interest in studying this issue resulted from a literature search in which we found supervision models, strategies and styles that should be part of the supervision process. However, no scientific evidence was found on the nurses' perceptions of the frequency with which the several distance clinical supervision strategies are implemented in their practices and the frequency with which they wanted them to be implemented.

Nursing practice is developed in two main settings: hospital or primary health care (PHC) settings. Given the different characteristics of these settings, and in order to ensure the effectiveness of reflective practice, the clinical supervisor must select the most appropriate supervision strategies for the specific context where the supervisee is working and the supervisee's personality and characteristics, with a view to optimizing his/her clinical performance and promoting his/her personal and professional development (Garrido, Simões, \& Pires, 2008).

The clinical supervisor must have good knowledge of the methodologies to be implemented and provide adequate resources to meet the supervisee's learning and developmental needs (Fowler, 2014). Distance supervision strategies allow the supervisee to access the clinical supervisor at any time, in real time or in an agreed-upon timeframe, so as to reflect on the practices and seek support. Thus, it is an important resource that may be used by the supervisor to facilitate the supervision process.

This study aimed to identify the frequency with which supervision strategies are implemented in hospital and PHC settings, as well as identify which are the distance supervision strategies that nurses from both settings would like to see more often implemented.

\section{Background}

CSN is a means for optimizing nurses' clinical performance. Therefore, in order to ensure its effectiveness in promoting nurses' personal and professional development, the clinical supervisor must have good knowledge of the most efficient methodologies, ensure that the supervisee has access to the appropriate clinical resources to his/ her learning and development needs, and adopt the adequate supervision strategies according to each supervisee's personality and characteristics, with the purpose of establishing a positive relationship conducive to learning and the accomplishment of the objectives (Fowler, 2014). Clinical supervisors should use different methodologies and strategies according to the supervisee's behavior, attitudes and expectations, which are essential for the success of the supervision process (Garrido et al., 2008).

Among the many supervision strategies available, distance supervision has been gaining importance given the social and technological advances over the past few years. These strategies have been more frequently adopted in countries and contexts where, due to the geographical distance, the direct contact between supervisor and supervisee is more difficult. In order to identify the most relevant distance supervision strategies in nursing, we reviewed the existing literature and scientific evidence, and selected the most important strategies in CSN: distance supervision: telephone, distance supervision: email and distance supervision: Skype ${ }^{\circledR}$.

The supervision strategies by telephone, email or Skype ${ }^{\circledR}$ allow supervisees to contact supervisors who are geographically distant, in real time or in an agreed-upon timeframe, so as to reflect on the 
practices and seek support. Supervision by telephone enables the clinical supervisor and the supervisee to schedule a convenient time, without the need for any cutting-edge technological equipment. At the agreed-upon time, the supervisor calls the supervisee and records his/her questions in a database, as well as other relevant data (Thompson \& Winter, 2004). Supervision by videoconference, namely using Skype ${ }^{\circledR}$ software, allows supervisors and supervisees to communicate orally and establish visual contact. Nurses prefer to use this strategy rather than using the telephone or email (Marrow, Hollyoake, Hamer, $\&$ Kenrick, 2002).

Primary health care nurses use distance supervision strategies more often than hospital nurses because of the difficulties in accessing the clinical supervisor in a timely and appropriate manner as a result of working in separate and often distant facilities (Marrow et al., 2002).

\section{Research questions}

This study aimed to answer the following questions: How often are distance supervision strategies implemented in hospital settings?; How often are distance supervision strategies implemented in PHC settings?; How often do nurses wish distance supervision strategies to be implemented in hospital settings?; How often do nurses wish distance supervision strategies to be implemented in PHC settings?; Are there any statistically significant differences between PHC nurses and hospital nurses concerning the desire for the implementation of distance supervision strategies?

\section{Methodology}

Taking into account the specific nature of the issue under discussion, we decided to use a quantitative approach. The choice of the quantitative paradigm is in line with Winstanley and White (2003), who argue for the need to develop instruments to assess the effectiveness of CSN, being essential the development of more quantitative research studies. We conducted a descriptive and exploratory study because we intended to obtain more information about this understudied phenomenon, particularly in Portugal.
With regard to temporality, we conducted a cross-sectional study since data were collected between May and September 2012.

The target population was composed of Portuguese nurses from different services of the São João Hospital Center, E.P.E. (CHSJ) and the Local Health Unit of Matosinhos, E.P.E. (ULSM), resulting in a sample of 273 nurses. In this study, we used mainly a non-probability convenience sampling and, with the purpose of increasing sample size and reducing standard deviation, we also used network sampling later on in the study.

Since we found no instrument in the literature review used to assess the frequency with which distance supervision strategies are implemented in health services, particularly in hospital and PHC settings, we developed a questionnaire for data collection - the Questionnaire of Frequency Assessment of Clinical Supervision in Nursing Strategies (QAFESCE; Questionário de Avaliação da Frequência de Estratégias de Supervisão Clínica em Enfermagem). The questionnaire was designed following the steps established by Fortin (2009): define the information to collect; build a database of questions; formulate questions; sort the issues; write the introduction and guidelines; submit the draft questionnaire to review; and, finally, submit the questionnaire to a pre-test. The validity of the QFACSNS was ensured by a group of national and international experts and a group of nurses who participated in the pre-test. The experts group was composed of 11 professionals: four nursing teachers from the United Kingdom, Ireland, Germany and Finland, six Portuguese nursing teachers (all with clinical and research experience in (SN) and one teacher in educational sciences. The group of experts reviewed the first version of the QFACSNS (version based on the literature review) with the purpose of assessing its content validity. Based on their feedback, we designed the second version of the QFACSNS which was pre-tested so as to assess the perceptions of nurses (representatives of the population) on the level of understanding and clarity of the questionnaire items and the representation of the CSN phenomenon. The pre-test group was intentionally composed of 10 nurses without training in CSN and nine nurses with training in this area, with the purpose of being representative of the population. Since the suggestions of the pre-test nurses did not change the content or shape of the questionnaire, 
a second pre-test was deemed unnecessary and all suggestions were integrated into the final version of the QFACSNS. We further tested the reliability of the QFACSNS by calculating the Cronbach's alpha coefficient, and obtained values higher than .90 .

With regard to data analysis, descriptive statistics were used, including frequencies, measures of central tendency and dispersion, and inferential statistics.

In order to comply with the ethical principles inherent to the research conducted with human subjects, we asked the Board of Directors and the Ethics Committee for Health of the CHSJ and the ULSM for permission to conduct the study. Permission was granted. All participants signed the informed consent form.

The frequency with which the distance supervision strategies are implemented and the frequency with which participants would like them to be implemented were assessed on a scale from 1 to 5 , in which 1 corresponded to one or more times per day, 2 to one or more times per week, 3 to one or more times per month, 4 to more than once per trimester, and 5 to never. To establish the ranking of the most often implemented strategies, we applied the following criterion: a higher percentage in score 1. If two strategies obtained the same percentage in a score, we would consecutively check the highest value obtained in scores 2, 3, 4, and 5. To establish the ranking of the distance supervision strategies which were never implemented, we performed the analysis in reverse order to the one previously explained.

\section{Results}

The 273 nurses who participated in the study were aged between 24 and 58 years ( $M=34$ years; SD $=7.05$ years), and $83.2 \%$ of them were female. The length of service ranged between one and 36 years $(\mathrm{M}$ $=11$ years; $\mathrm{SD}=6.77$ years), and $64.3 \%$ worked in hospital settings.

Hospital nurses reported supervision by email as the most often implemented distance supervision strategy (Table 1). This strategy and supervision by telephone obtained the same percentage in score 1 (5.7\%), and supervision by email obtained the highest percentage in score 2 (13.7\% vs. $8.6 \%$, respectively). Supervision by Skype ${ }^{\circledR}$ was mentioned by nurses as being the least frequently implemented strategy (5.1\% in score 1) and also the one reported by most nurses (78.9\%) as never being implemented. Supervision by email was the least reported strategy as never being implemented (57.1\%).

Table 1

Frequency of implementation of distance supervision strategies in hospital settings

\begin{tabular}{lccccc}
\hline Distance supervision strategies & \multicolumn{5}{c}{ \% in scores } \\
& 1 & 2 & 3 & 4 & 5 \\
\hline Distance supervision: telephone & 5.7 & 8.6 & 12.6 & 12.6 & 60.6 \\
Distance supervision: email & 5.7 & 13.7 & 8.6 & 14.9 & 57.1 \\
Distance supervision: Skype ${ }^{\circledR}$ & 5.1 & 5.7 & 5.7 & 4.6 & 78.9 \\
\hline
\end{tabular}

PHC nurses reported that supervision by email was and supervision by Skype ${ }^{\circledR}$ was most often reported the most frequently implemented strategy (10.3\%), as never being implemented (68.0\%; Table 2).

Table 2

Frequency of implementation of distance supervision strategies in PHC settings

\begin{tabular}{lccccc}
\hline Distance supervision strategies & \multicolumn{5}{c}{ \% in scores } \\
& 1 & 2 & 3 & 4 & 5 \\
\hline Distance supervision: telephone & 5.2 & 14.4 & 18.6 & 14.4 & 47.4 \\
Distance supervision: email & 10.3 & 19.6 & 15.5 & 18.6 & 36.1 \\
Distance supervision: Skype $^{\circledR}$ & 4.1 & 8.2 & 11.3 & 8.2 & 68.0 \\
\hline
\end{tabular}


When comparing the rankings obtained in hospital settings (Table 1) and PHC (Table 2), we concluded that the most often used strategy is the same, i.e. supervision by email. Distance supervision by Skype ${ }^{\circledR}$ was the most often reported strategy as never being used in both settings, and supervision by email was the least reported strategy as never being implemented. With regard to the strategy that participants would like to see more frequently implemented, we found that hospital nurses (Table 3) prefer distance supervision by email (11.4\%). Supervision by Skype ${ }^{\circledR}$ was the nurses' least preferred strategy to be implemented in their services (5.7\%), as well as the one that most nurses reported as never wanting it to be implemented (40.6\%).

Table 3

Frequency of the desire for implementation of distance supervision strategies in hospital settings

\begin{tabular}{lccccc}
\hline \multirow{2}{*}{ Distance supervision strategies } & \multicolumn{5}{c}{ \% in scores } \\
& 1 & 2 & 3 & 4 & 5 \\
\hline Distance supervision: telephone & 7.4 & 20.0 & 20.6 & 21.7 & 30.3 \\
Distance supervision: email & 11.4 & 22.9 & 23.4 & 24.0 & 18.3 \\
Distance supervision: Skype $^{\circledR}$ & 5.7 & 16.6 & 16.0 & 21.1 & 40.6 \\
\hline
\end{tabular}

In PHC, distance supervision strategy by email was the one that most participants wanted to see more frequently implemented (16.5\%). Supervision by Skype $^{\circledR}$ was the least preferred by nurses to be

Table 4

Frequency of the desire for implementation of distance supervision strategies in PHC settings

\begin{tabular}{llllll}
\hline \multirow{2}{*}{ Distance supervision strategies } & \multicolumn{5}{c}{ \% in scores } \\
& 1 & 2 & 3 & 4 & 5 \\
\hline Distance supervision: telephone & 13.4 & 17.5 & 33.0 & 21.6 & 14.4 \\
Distance supervision: email & 16.5 & 29.9 & 25.8 & 20.6 & 7.2 \\
Distance supervision: Skype $^{\circledR}$ & 9.3 & 15.5 & 22.7 & 18.6 & 34.0 \\
\hline
\end{tabular}

When comparing the percentages obtained in score 1 concerning the distance supervision strategies reported by hospital nurses as being the most often implemented strategies with those that they would like to see more often implemented (Figure 1), we found that nurses wanted the three distance supervision implemented in their services (9.3\%; Table 4), as well as the one that most nurses wanted never to be implemented (34\%).

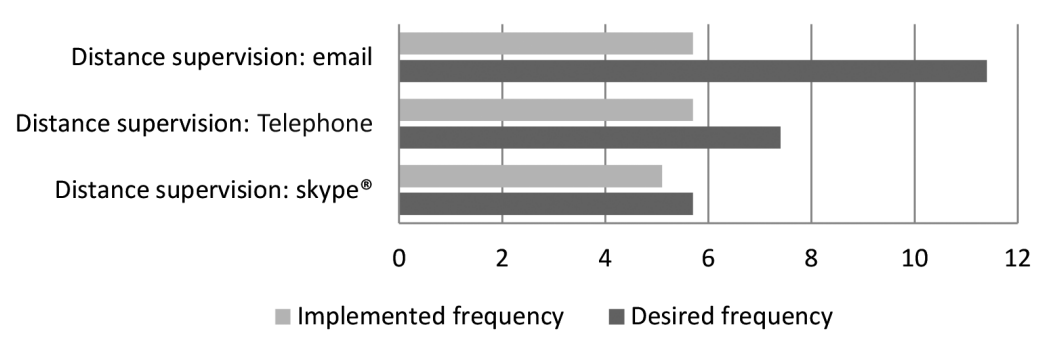

Figure 1. Distance supervision strategies more frequently implemented and desired in hospital settings.

strategies to be more frequently implemented than they actually are. The strategy with the highest percentage difference between the implemented and desired score was the supervision by email (5.7\%). The differences in the supervision by telephone and by Skype ${ }^{\circledR}$ were $1.7 \%$ and $0.6 \%$, respectively. 
When comparing the percentages obtained in score 1 of the distance supervision strategies that PHC nurses reported as being more often implemented with those that they wanted to be more often implemented (Figure 2), we found that nurses wanted the three distance supervision strategies to be more frequently implemented than they actually are. The strategy with the highest percentage difference between the score implemented and desired was the supervision by telephone ( $8.2 \%)$. The differences in the supervision by email and by Skype ${ }^{\circledR}$ were $6.2 \%$ and $5.2 \%$, respectively.



Figure 2. Distance supervision strategies more frequently implemented and desired in PHC settings.

We found statistically significant differences between PHC and hospital nurses concerning the desire to implement the strategies distance supervision: telephone $(\mathrm{U}=6957.0 ; p=.012)$ and distance supervision: email $(\mathrm{U}=6885.0 ; p=.008)$, whose implementation was less desired by hospital nurses (Table 5).

\section{Table 5}

Results of the Mann-Whitney U-Test concerning the desire to implement distance supervision strategies depending on the workplace

\begin{tabular}{lccc}
\hline & PHC $(n=97)$ & Hospital $(n=175)$ & \\
& Mean rank order & Mean rank order & $p$ \\
\cline { 2 - 4 } Distance supervision: telephone & 120.72 & 145.25 & .012 \\
Distance supervision: email & 119.98 & 145.65 & .008 \\
\hline
\end{tabular}

\section{Discussion}

We concluded that the only distance supervision strategy which was more implemented in PHC than in hospital settings was the supervision by email. This is not consistent with the results obtained by Marrow et al. (2002), who reported that distance supervision strategies are widely used in PHC. We believe that this result may be explained by the fact that the sampled PHC nurses work in institutions located in costal, non-isolated urban areas and have extensive nursing teams. This is one of the limitations of this study. We also believe that the managers of health care organizations, mainly PHC centers, should explain to nurses the different advantages of these strategies and, subsequently, their implementation, and that the whole process should be assessed.
Data on the frequency concerning the nurses' desire for distance supervision strategies to be implemented in hospital and PHC settings are new knowledge that emerges from this research due to the lack of national or international studies on this topic. When comparing the ranking of the desire to see the distance supervision strategies implemented reported by PHC and hospital nurses, we concluded that $\mathrm{PCH}$ nurses want all of them to be more implemented. Based on these results, we believe that the fact that hospital nurses have more sharing moments, particularly during shift turnover, the development of a teamwork-based methodology can make nurses feel personally supported (face to face), without needing to implement these strategies. It should be noted that both PHC and hospital nurses want distance supervision strategies to be 
more frequently implemented than they actually are. Therefore, this aspect, as well as the many benefits of these strategies, must be taken into account when implementing CSN programs.

\section{Conclusion}

This study contributed to improve the existing knowledge on CSN since it answered the formulated research questions. However, we suggest that it be replicated in health care centers in the more geographically isolated rural and interior regions areas in order to check if the nurses in these regions use more distance supervision strategies.

In fact, the relevance of an instrument that identifies the implemented distance supervision strategies and those that nurses would like to see more often implemented in health contexts is undeniable. It is only by assessing the nurses' perceptions of the implementation of CSN in their workplace, namely the strategies that are currently implemented, that we can assess if these are being effectively implemented, and suggest changes to less appropriate aspects.

Despite the scientific evidence on the implementation and development of CSN programs, as well as on the training needs, further research is needed on this topic so as to optimize the effectiveness of these programs. There is an urgent need for studies in the area of CSN strategies, and these results can be used as a basis for planning CSN programs adjusted to specific contexts. A CSN program developed based on supervision strategies identified by nurses as being the most relevant and appropriate to their context may contribute to increase the motivation and involvement of these professionals throughout the process, to the extent that they develop a sense of ownership for the change.

\section{References}

Cruz, S., Carvalho, A., \& Sousa, P. (2014). Clinical supervision: Priority strategy to a better health. Procedia: Social and Behavioral Sciences, 112(1), 97-101. doi: 10.1016/j. sbspro.2014.01.1143

Dilworth, S., Higgins, I., Parker, V., Kelly, B., \& Turner, J. (2013). Finding a way forward: A literature review on the current debates around clinical supervision. Contemporary Nurse, 45(1), 22-32. doi: 10.5172/conu.2013.45.1.22

Evans, C., \& Marcroft, E. (2015). Clinical supervision in a community setting. Nursing Times, 111(22), 16-18.

Fortin, M. (2009). Fundamentos e etapas do processo de investigação. Loures, Portugal: Lusodidacta.

Fowler, J. (2014). Clinical supervision: From staff nurse to nurse consultant. Part 12: Series summary. British Journal of Nursing, 23(2), 114.

Francke, A., \& Graaff, F. (2012). The effects of group supervision of nurses: A systematic literature review. International Journal of Nursing Studies, 49(9), 1165-1179. doi: 10.1016/j. ijnurstu.2011.11.012

Garrido, A., Simões, J., \& Pires, R. (2008). Supervisão clínica em enfermagem: Perspetivas práticas. Aveiro, Portugal: Universidade de Aveiro.

Macedo, A. (2012). Supervisão em enfermagem: Construir as interfaces entre a escola e o bospital. Santo Tirso, Portugal: De Facto Editores.

Marrow, C., Hollyoake, K., Hamer, D., \& Kenrick, C. (2002). Clinical supervision using video-conferencing technology: A reflective account. Journal of Nursing Management, 10(5), 275-282. doi: 10.1046/j.1365-2834.2002.00313.x

McColgan, K., \& Rice, C. (2012). An online training resource for clinical supervision. Nursing Standard, 26(24), 35-39. doi: 10.7748/ns2012.02.26.24.35.c8945

Silva, R., Pires, R., \& Vilela, C. (2011). Supervisão de estudantes de enfermagem em ensino clínico: Revisão sistemática da literatura. Revista de Enfermagem Referência, 3(3), 113-122. doi: 10.12707/RIII1036

Thompson, S., \& Winter, R. (2004). A telephone led clinical supervision pilot for nurses in different settings. Professional Nurse, 18(8), 467-470.

Winstanley, J., \& White, E. (2003). Clinical supervision: Models, measures and best practice. Nurse Researcher, 10(4), 7-38. doi: $10.7748 / \mathrm{nr} 2003.07 .10 .4 .7 . c 5904$ 
